\title{
Editorial
}

\section{Aquatic Sciences - Research Across Boundaries is an online first journal!}

Starting in March 2005, Aquatic Sciences - Research Across Boundaries $(A S)$ is an online first journal: articles will be published on the web as soon as publishable (ASAP), i.e. a few days after the return of corrected galley proofs. The electronic version of the full text of articles, including ASAP papers, is accessible to $A S$ subscribers and to "Multiple Users" of SpringerLink. Twelve months after the cover date of the printed issue, the electronic version of $A S$ also is accessible to institutions and individuals that are not subscribers to $A S$ or "Multiple Users" of SpringerLink. Furthermore, a special annual subscription price of $€ 88$.- is offered to members of any scientific society (e.g., ASLO, EUG, SIL, NABS).

Other good news is that the re-launch of Aquatic Sciences in 2002 has resulted in an increase in the $A S$ impact factor, now 1.049 (2003), based on the years 2001 and 2002, and we expect that the $A S$ impact factor will increase further. We feel that special issues and special features contribute to the success of the Journal. The following special issues and special features have been published since the re-launch of $A S$ :

- Vulnerability of Water Resources to Environmental Change - A Systems' Approach (AS 64/4)

- Using Artificial Floods for Restoring River Integrity (AS 65/3)

- Impact of Photochemical Processes in the Hydrosphere (AS 65/4)

- Biogeochemical Controls on the Mobility and Bioavailability of Metals in Soils and Groundwater (AS 66/1)

- Abundance and Functions of Natural Organic Matter Species in Soil and Water (AS 66/2)

- Aquatic Resources in Arid Lands: Issues and Opportunities (AS 66/4)

- Riparian Perspectives of International Cooperation in the Eastern Nile Basin (this issue)
I thank the Guest Editors of these special issues and special features for their initiative and efforts.

Aquatic Sciences - Research Across Boundaries also publishes submitted original research papers, reviews and overviews that are not part of a special issue or special feature. Since $A S$ spans the range from molecular-level mechanistic studies to investigations at the whole ecosystem scale, these papers are published under the following sections:

- Molecular-Level and Mechanistic Studies

- Biogeochemical Studies

- Ecosystem Studies

- Water Policy

The Water Policy section is essential to the Journal since in addition to natural sciences' investigations of aquatic systems, socio-economic aspects of water issues are needed as a basis for sound political decisions and actions. A high scientific standard by a rigorous review process is warranted also for water policy articles. However, in some cases $A S$ publishes articles that are not the usual type of contribution to a scholarly journal but because they are of strong political interest and may stimulate further policy-oriented debates (see also Preface to the Special Feature "Riparian Perspectives of International Cooperation in the Eastern Nile Basin", this issue). To quote Albert Einstein "Not everything that can be counted counts, and not everything that counts can be counted".

Barbara Sulzberger, Editor-in-Chief (aquatic.sciences@eawag.ch) 